\title{
Terapia do riso e formação em saúde
}

\author{
Antonio Correa Neto ${ }^{1}$
}

${ }^{1}$ Faculdades Anhanguera - Santo André (SP), Brasil. E-mail: antablado@gmail.com

DOI: http://dx.doi.org/10.7322/abcshs.v41i3.901

Neste fascículo da ABCS Health Science, encontramos um estudo de Coutinho, Lima e Bastos ${ }^{1}$ sobre a utilização e benefícios da terapia do riso na ótica dos estudantes de enfermagem da Universidade Estadual de Feira de Santana. A pesquisa partiu de uma amostragem de 70 estudantes, sendo utilizado questionário individual composto de questões abertas e fechadas.

Como conclusão da pesquisa, observou-se a necessidade de propagar, principalmente no âmbito acadêmico, a utilização de terapias integrativas (a exemplo da terapia do riso) como instrumento para o cuidar em enfermagem, visto que essa prática melhora a interação interpessoal e a humanização no ambiente hospitalar.

Nos últimos anos, inspirados por ações como as do Instituto Gesundheit, do médico americano Path Adams, e do grupo paulistano Doutores da Alegria, temos visto o crescente interesse de alunos da área de saúde na utilização do humor como potente ferramenta no contato humanizado com o paciente, criando grupos de atuação dentro dos leitos hospitalares.

Visando ao bem-estar do paciente, essas práticas flutuam entre a simples animação inconsequente e as visitas sistematizadas, com acompanhamentos de outros profissionais, delineando objetivos claros que podem ou não sofrer alterações conforme as visitas vão acontecendo. Além disso, perfazem vínculos dentro da mútua confiança, dilatam tempos e espaços que não visam à cura, mas ao enfrentamento do período de internação, sendo muitas e diferentes as formas de abordagens: levar o adulto ao contato com sua criança interior através de brincadeiras; usos de técnicas orientais para relaxamento e criação de um ambiente propício para, na sequência, obter o riso através de exercícios cômicos; contação de histórias cômicas acompanhadas de paródias sobre o cotidiano; ou mesmo o uso de personagens clownescos que utilizam o nariz vermelho, conhecido como a menor máscara do mundo e que é um código facilitador, criando, na maioria das vezes, uma empatia com o ambiente hospitalar e, por conseguinte, com o paciente.

Segundo Ayres², humanização é a permeabilidade entre o técnico e o não técnico, funcionando como o diálogo entre essas duas dimensões interligadas que possibilita maiores autenticidade e efetividade ao encontro terapêutico, sendo diferenciado, ético e humanizado com o paciente e o ambiente hospitalar.

O autor entende humanização como um conjunto de proposições cujo norte ético e político é o compromisso das tecnociências da saúde, em seus meios e fins, com a realização de valores relacionados à felicidade humana e democraticamente validados como bem comum.

Podemos aferir que essa dimensão humanizadora se dá no encontro entre os pacientes e os profissionais de saúde, sendo a terapia do riso potencializadora desse encontro, pois carrega em sua premissa a felicidade dos sujeitos envolvidos.

Encontramos, hoje, vários grupos consolidados, com anos de atividade, preservando uma prática permanente, como: "Sorrir é Viver", da Faculdade de Medicina do ABC; "Médicos da Alegria", da Faculdade de Medicina de Botucatu; "Palhaçoterapia”, da Universidade de Pernambuco.

Esse movimento, impulsionado pelos próprios graduandos, resultou em um congresso internacional, o "M.C.A. Saúde, Cultura e Arte", que já está em sua sétima edição no qual, entre outros temas afins, tem como principal a discussão de um currículo que agregue a humanização das práticas em saúde e a importância da arte dentro desse contexto.

Segundo Silva e Omura ${ }^{3}$, embora os estudos tenham aumentado significativamente nos últimos anos, a escassez de publicações em língua portuguesa sobre a terapia do riso e suas implicações na formação dos profissionais de saúde dificulta o acesso aos resultados, bem como a maior propagação nos meios relacionados à saúde; ainda, o tema nos fornece ricas conexões com as formas de ver e de sentir a ação terapêutica, (re) significando os dizeres e fazeres que emanam dessa experiência.

Assim, fomentar a necessária publicação de mais pesquisas científicas que retratem as vantagens e os benefícios da utilização dessa prática como terapia no ambiente hospitalar e seu impacto nos futuros profissionais da área de saúde deve ser recebida com muitos sorrisos de felicidades.

\section{REFERÊNCIAS}

1. Coutinho MO, Lima IC, Bastos RA. Terapia do riso como instrumento para processo de cuidado na ótica dos acadêmicos de enfermagem. ABCS Health Sci. 2016;41(3):163-7. http://dx.doi.org/10.7322/abcshs.v41i3.906

2. Ayres JR. Cuidado: trabalho e interação nas práticas de saúde. Rio de Janeiro: CEPESC-IMS/UERJ; 2009.
3. Silva PH, Omura CM. Utilização da risoterapia durante a hospitalização: um tema sério e eficaz. Rev Enferm UNISA. 2005;6:70-3 